\title{
Catalytic Non-redox Carbon Dioxide
}

\section{Fixation in Cyclic Carbonates}

Saravanan Subramanian ${ }^{1}$, Doyun Kim², Thien S. Nguyen"1,

Mousumi Garai ${ }^{1}$, Wonki Lim², Cafer T. Yavuz ${ }^{1,2,3,4 *}$

${ }^{1}$ Graduate School of EEWS, Korea Advanced Institute of Science and Technology (KAIST) 2Department of Chemical and Biomolecular Engineering, KAIST,

${ }^{3}$ Department of Chemistry, KAIST,

${ }^{4}$ Saudi-Aramco - KAIST $\mathrm{CO}_{2}$ Management Center, KAIST 


\section{Introduction}

\section{Accelerated Warming}

3.0

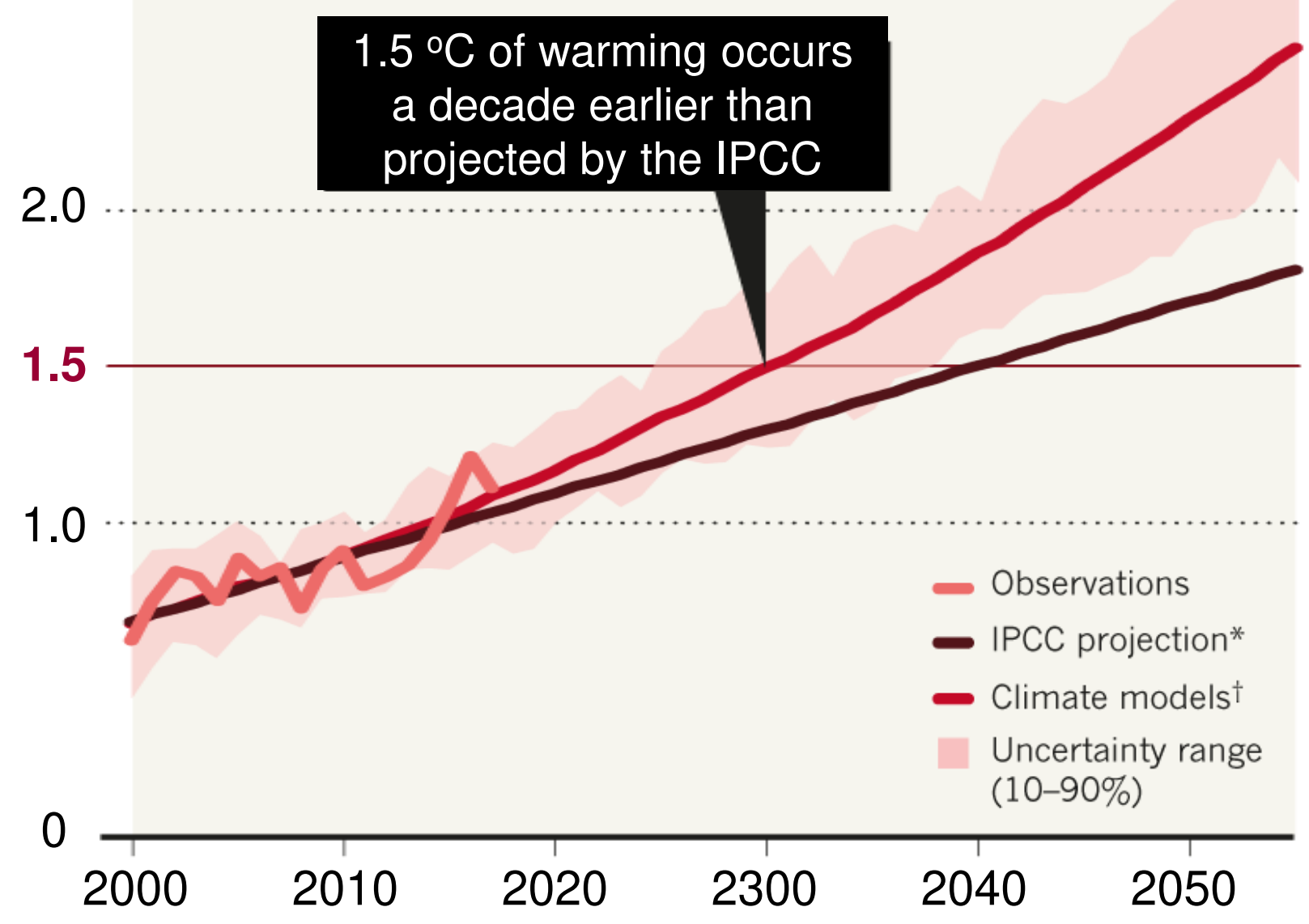

Nature 564, 30-32 (2018) 


\section{Non-redox $\mathrm{CO}_{2}$ Utilization}

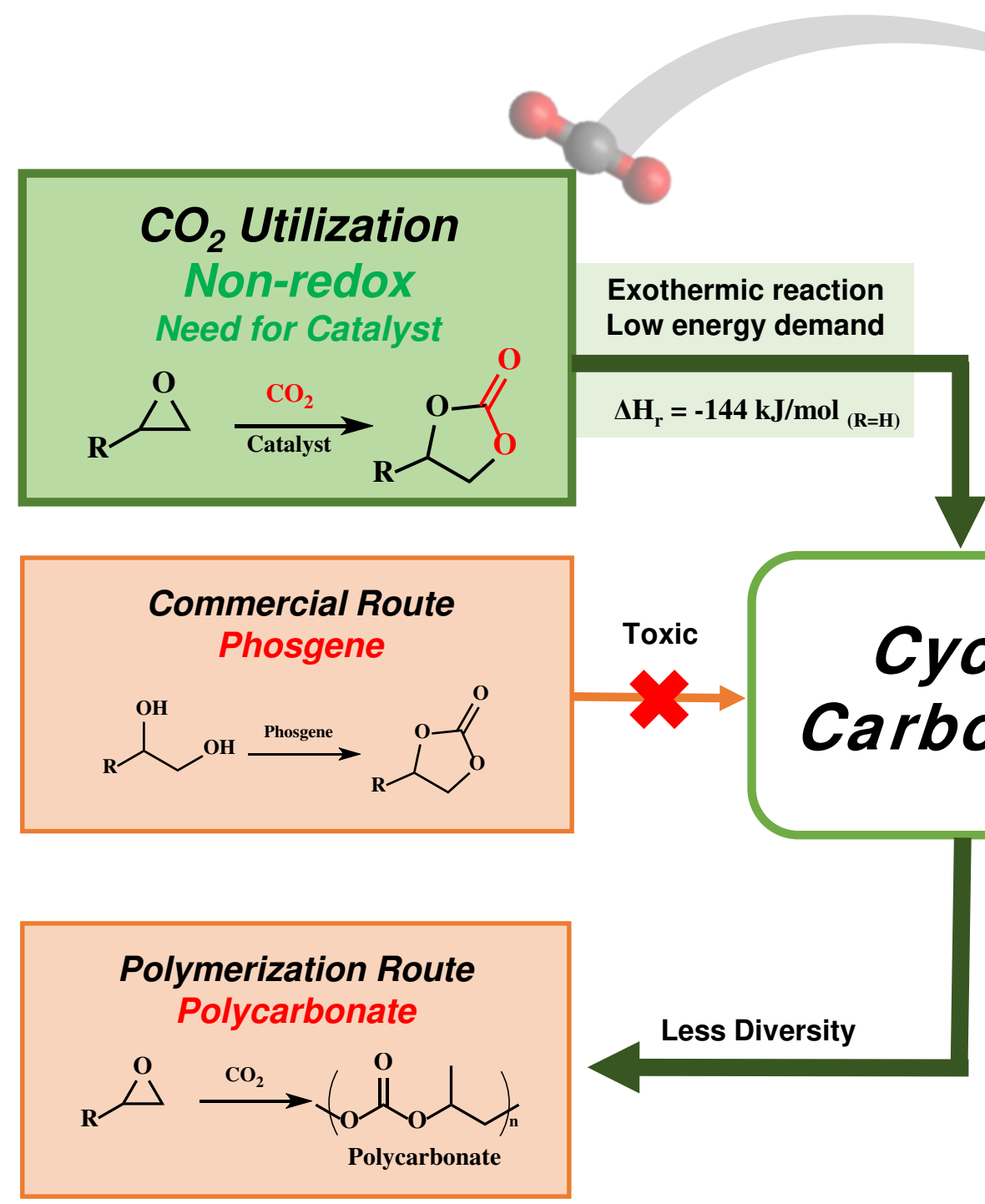

\section{Applications}

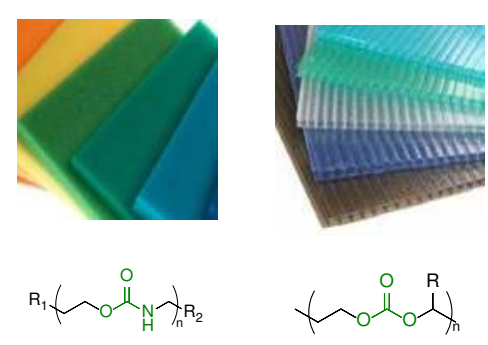

Polyurethane Polycarbonate

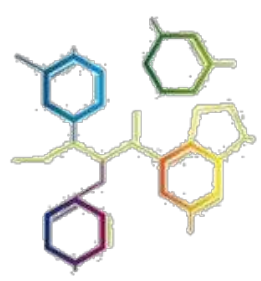

Synthesis Precursor

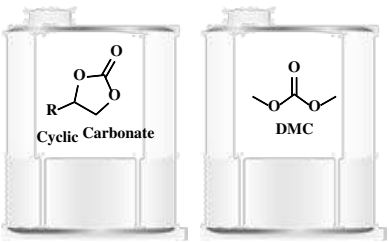

Electrolyte or Solvent 


\section{State of the Art in Heterogeneous Catalyst}

Current Heterogeneous System

- Low Reactivity, Selectivity

- Deactivation

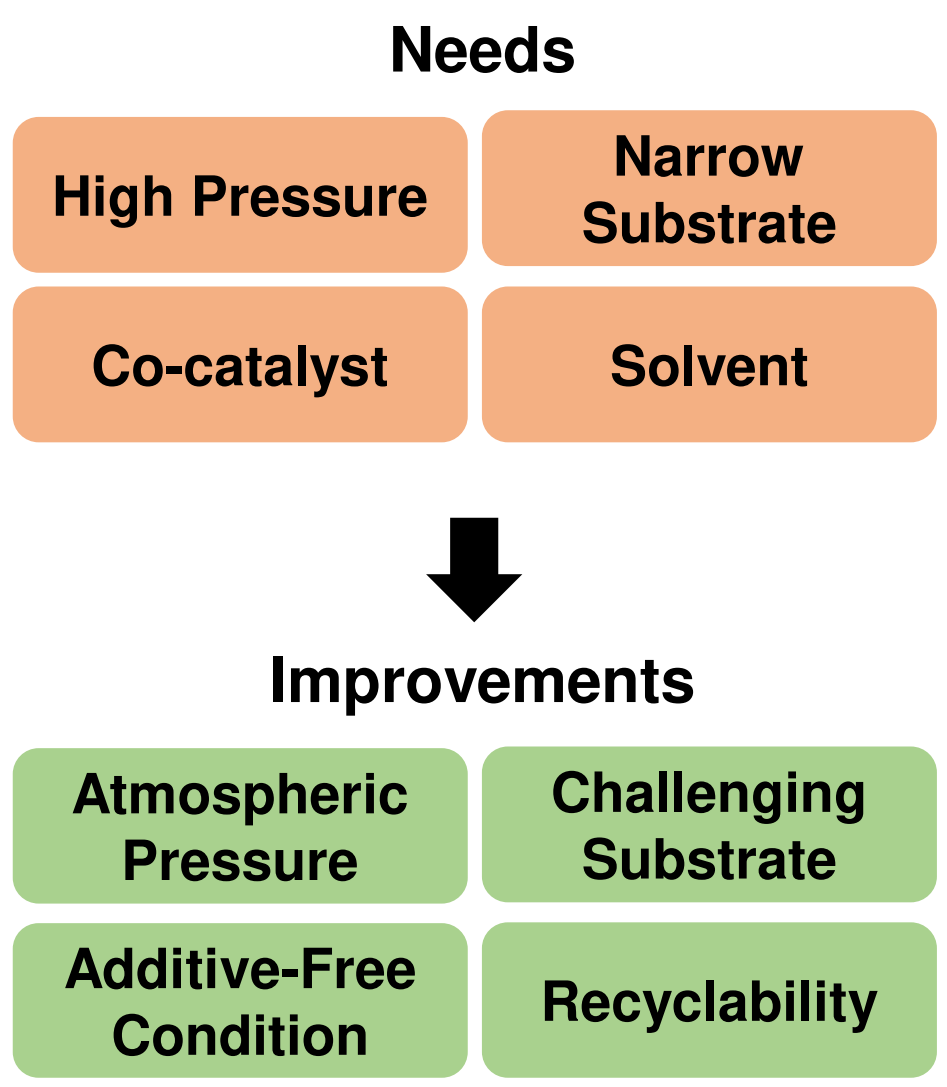

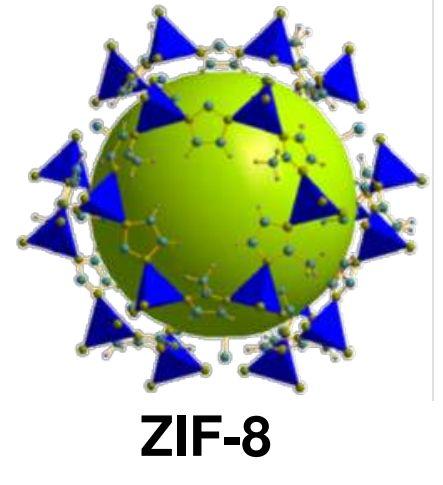

ACS Catalysis 20122 (1), 180-183

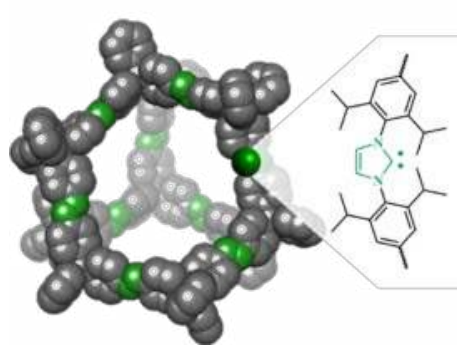

Nanoporous NHC

Chem. Mater. 2015, 27, 19, 6818-6826

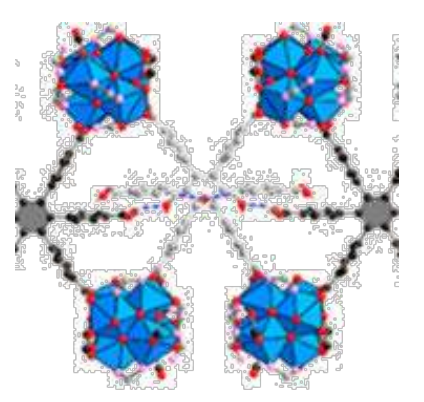

MOF-892

ACS Appl. Mater. Interfaces, 2018, 10 (1), 733-744

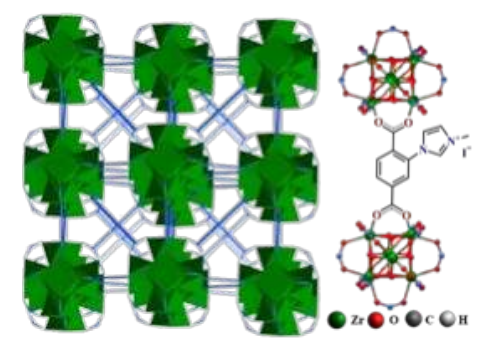
Imidazole-MOF

Chem. Commun., 2018, 54, 342 Condition 


\section{Novel Imidazolinium-based COP-222}

\section{Imidazolinium-based Covalent Organic Polymer (COP)-222}

A

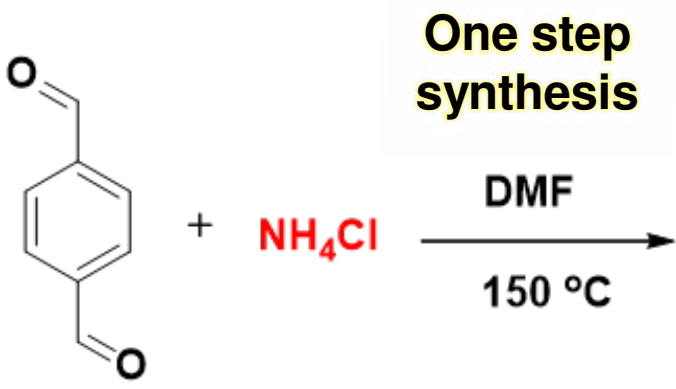

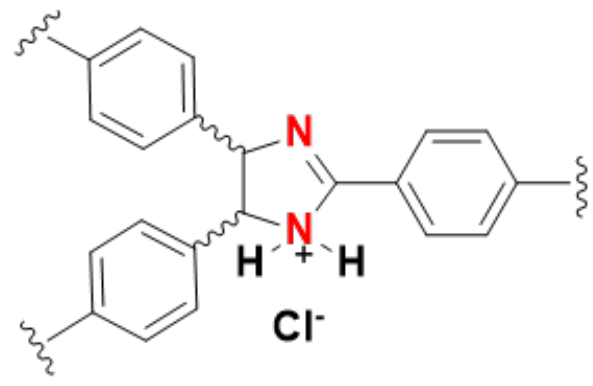

COP-222
C

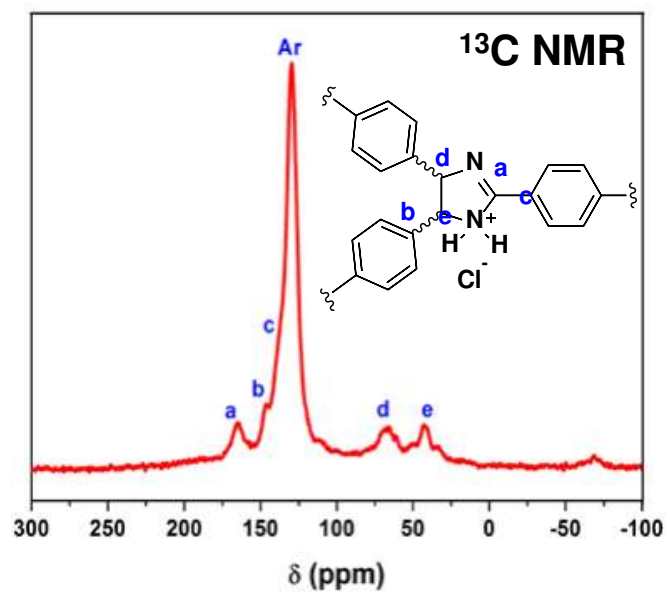

D

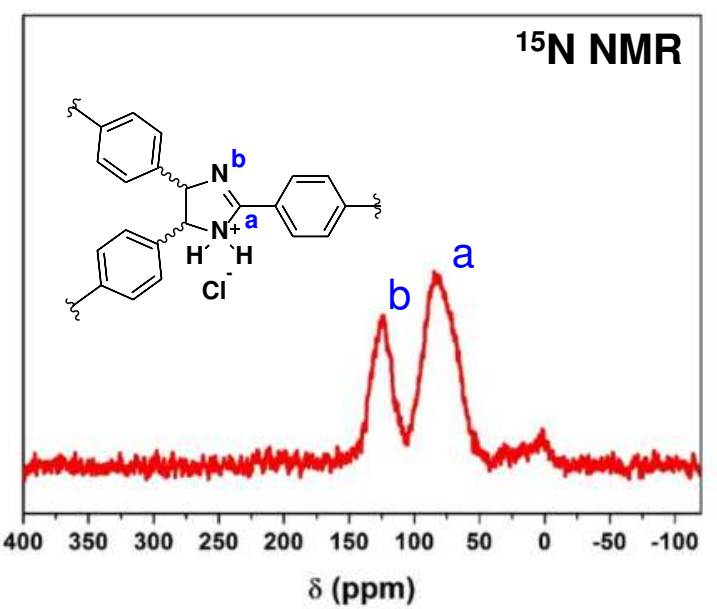

B

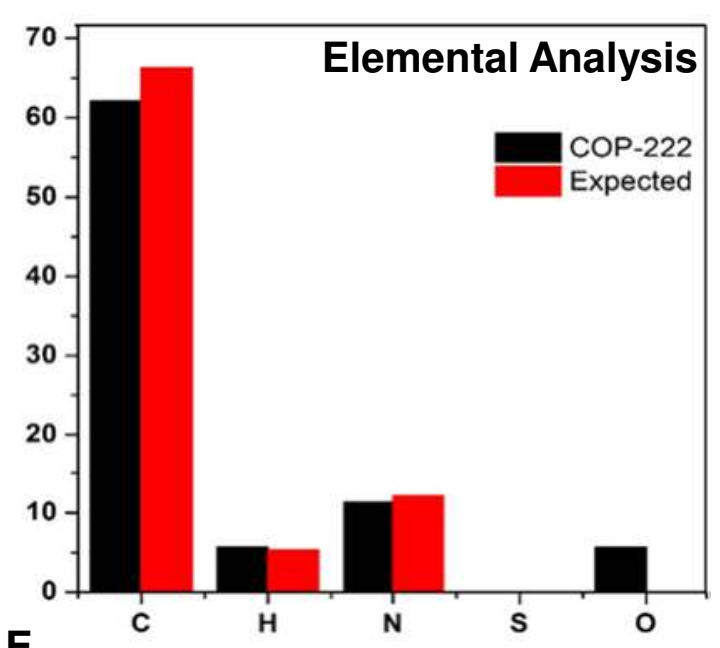

E

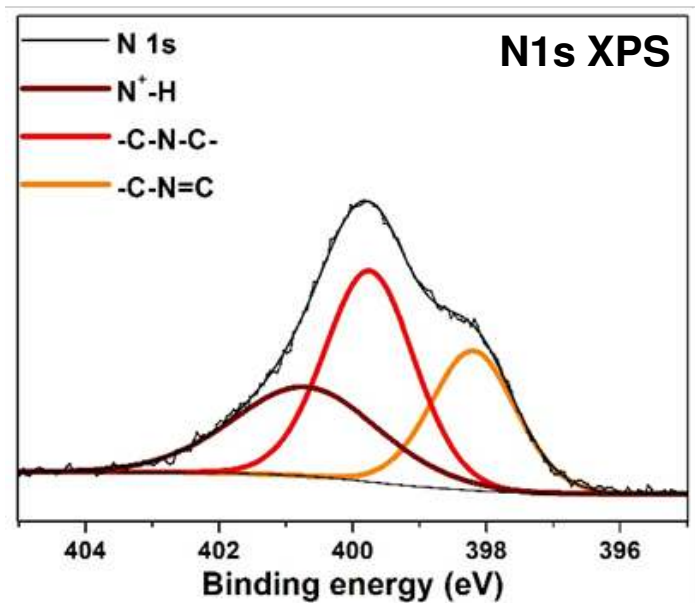

Figure 1. Synthesis and imidazolinium characterization of COP-222 (A) One-step, one-pot synthesis from commercially available substrates. (B) Elemental analysis $(\mathrm{C}, \mathrm{N}, \mathrm{H}, \mathrm{O})$ with expected imidazolinium structure (C) Experimental ${ }^{13} \mathrm{C}-\mathrm{NMR}$. (D) ${ }^{15} \mathrm{~N}-\mathrm{NMR}$ with ${ }^{15} \mathrm{~N}$ enriched COP-222. (E) XPS (N-1s) data. 


\section{Physicochemical Property of COP-222}

\section{XRD, SEM, BET, $\mathrm{CO}_{2}$ Isotherm, and TPD Analysis}

A
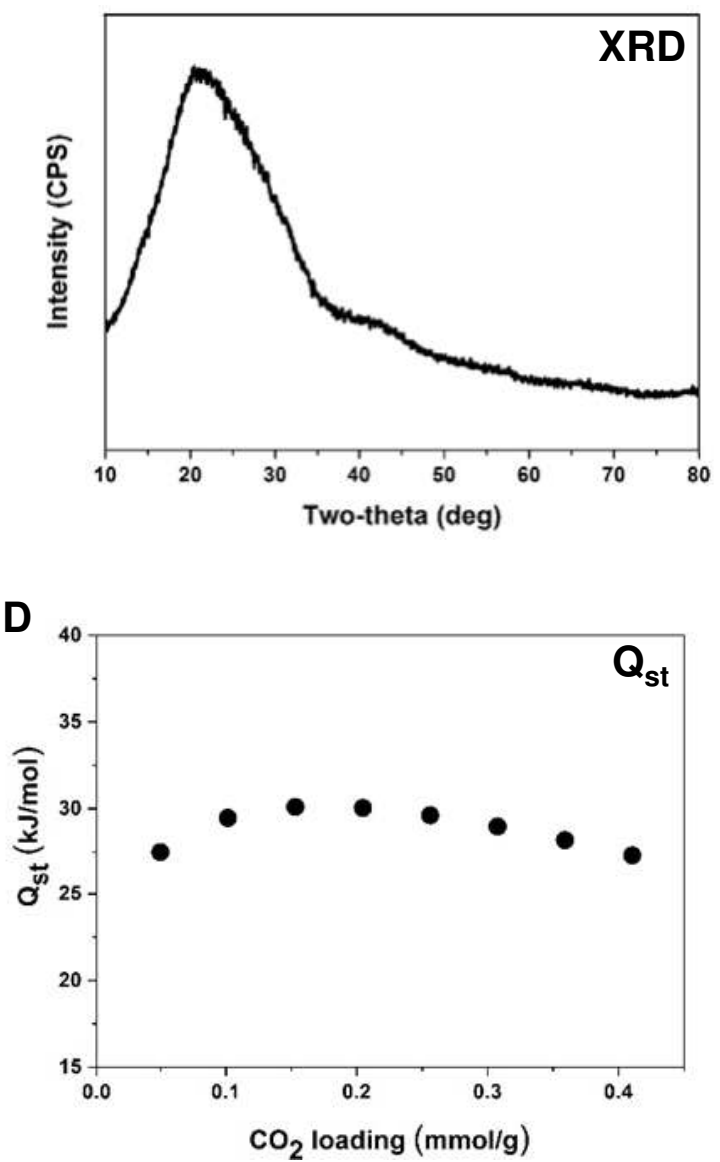

B

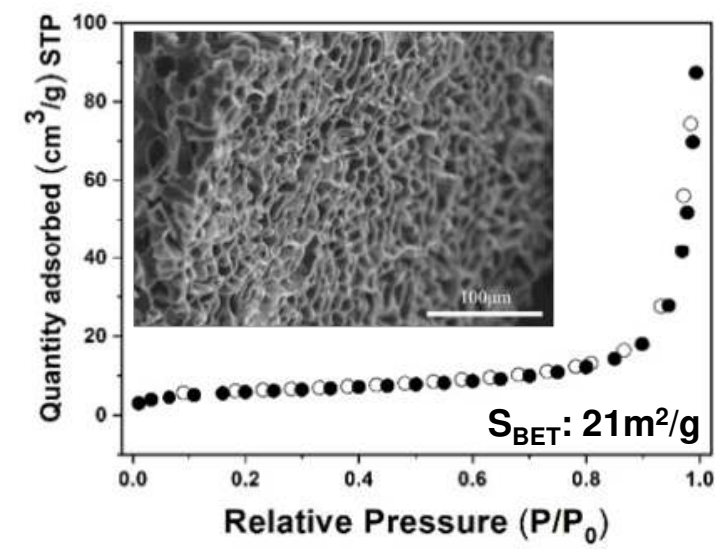

E

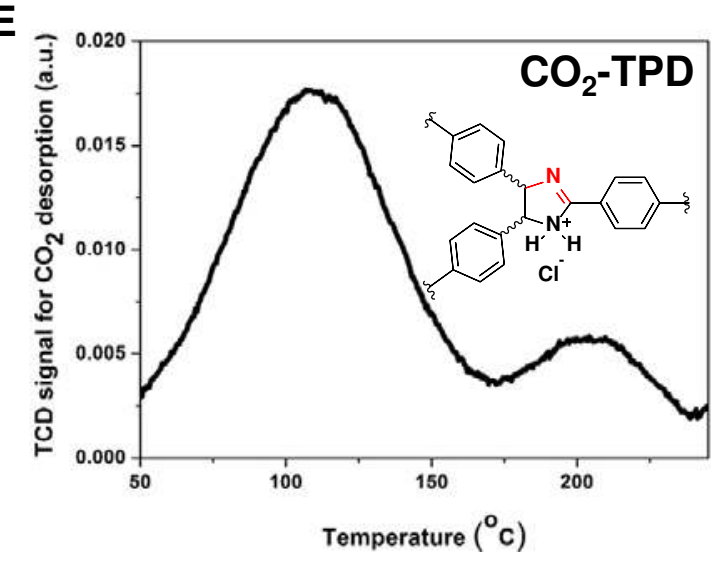

C

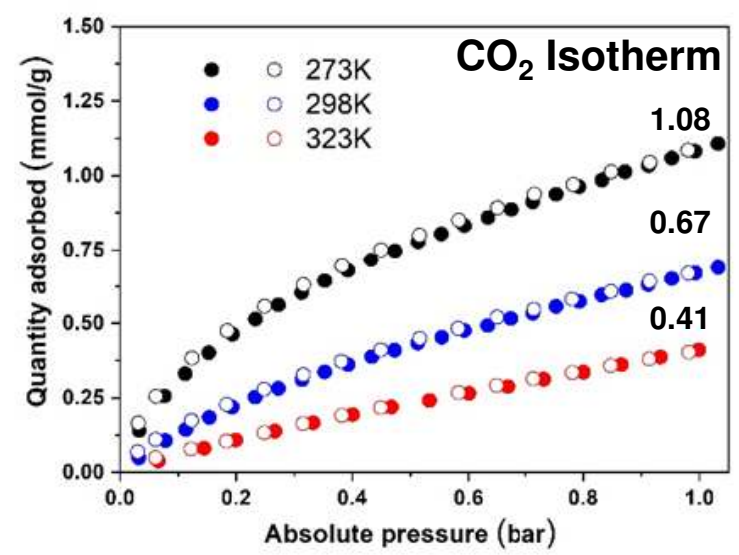

$\mathbf{F}$

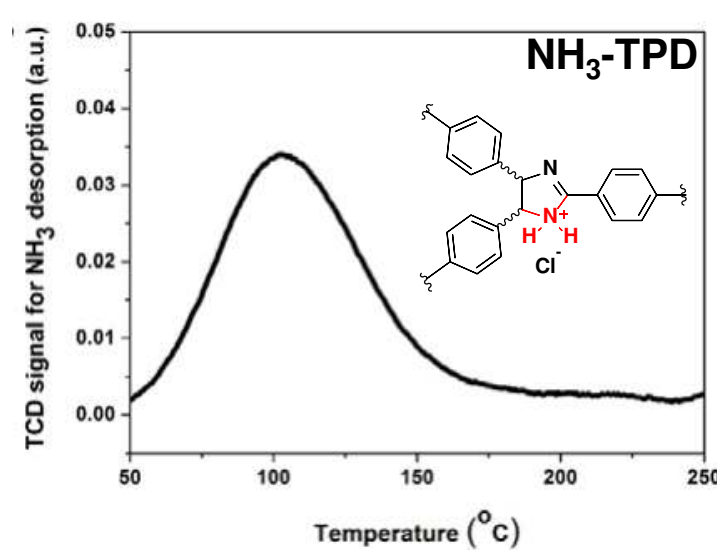

Figure 2. Physicochemical characterization of COP-222 (A) XRD pattern reflects amorphous nature. (B) $\mathrm{N}_{2}$ adsorption-desorption isotherm at $77 \mathrm{~K}$ indicates non-porous architecture. Inset displays scanning electron microscopy image of COP-222 (C) $\mathrm{CO}_{2}$ adsorption isotherm at different temperature: 273 , 298, and 323K. (D) Isosteric heat of adsorption $\left(\mathrm{Q}_{\mathrm{st}}\right)$ data of COP-222 using Clausius-Clapeyron equation. Temperature programmed desorption profiles of COP-222 (E) $\mathrm{CO}_{2}$-TPD curve (F) $\mathrm{NH}_{3}$-TPD curve. 


\section{Optimization of Catalytic Activity}

\section{Cycloaddition Reaction of $\mathrm{CO}_{2}$ with Epoxides}

A

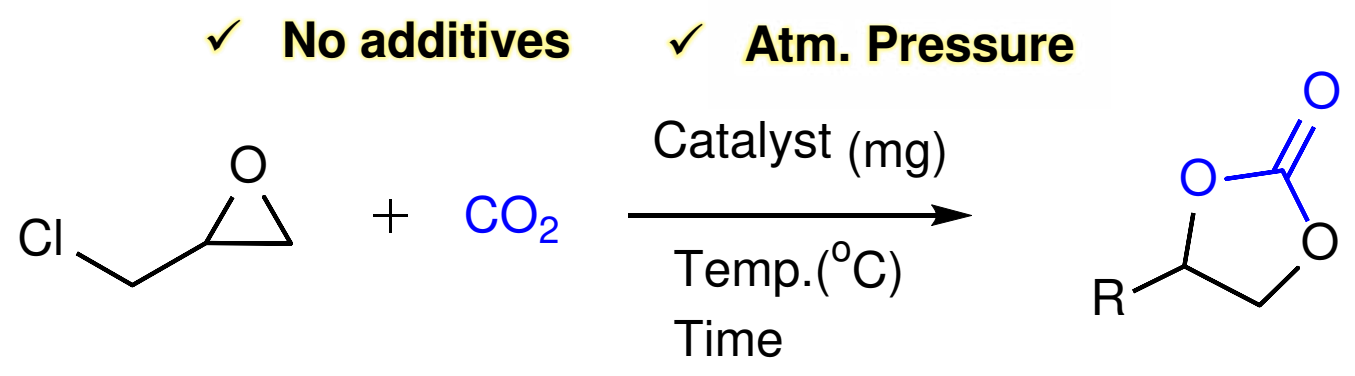

$\checkmark$ Catalytic activity: Selectivity $>99 \%$, Yield 99\%

C

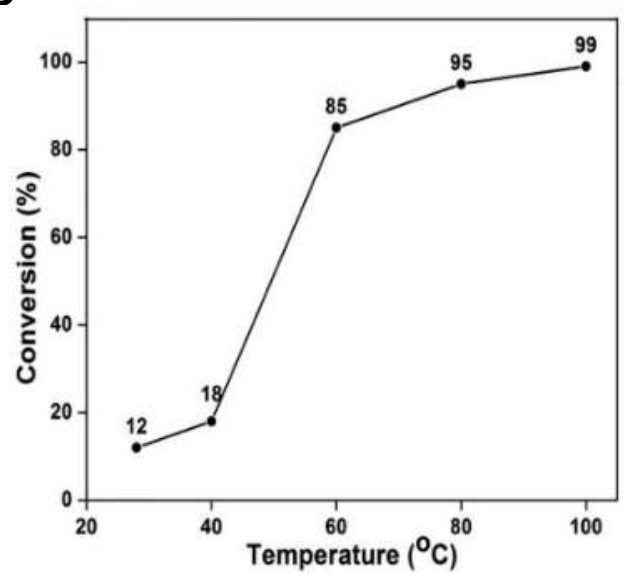

D

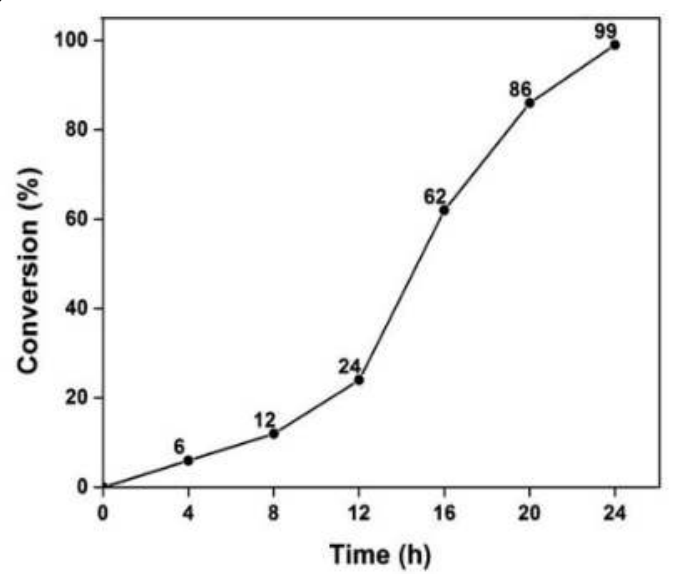

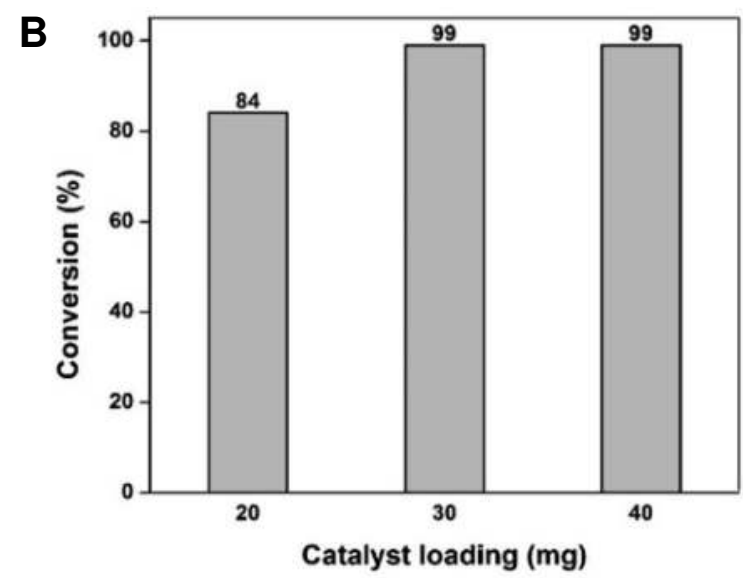

E

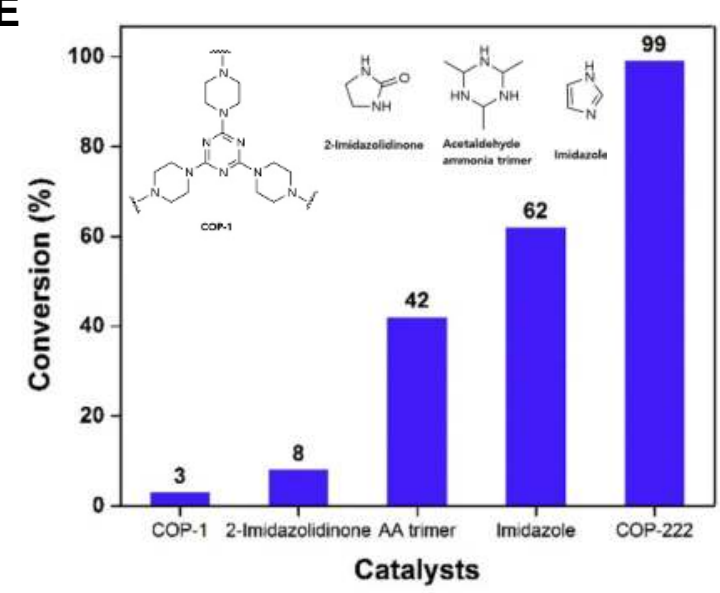

Figure 3. Optimization of catalyst activity (A) Cycloaddition of $\mathrm{CO}_{2}$ to epichlorohydrin was used to optimize catalytic activity. (B) Screening of catalyst loading. (C) Screening of temperature.(D) Conversion with respect to time. (E) Screening of control structures for the cycloaddition reaction. Reaction conditions: catalyst, epichlorohydrin (5mmol), and $\mathrm{CO}_{2}$ (1atm).Conversions were determined by using ${ }^{1} \mathrm{H} \mathrm{NMR}$. 


\section{Substrate Scope and Recyclability}

\section{Wide substrate scope}

A

Easy

substrates
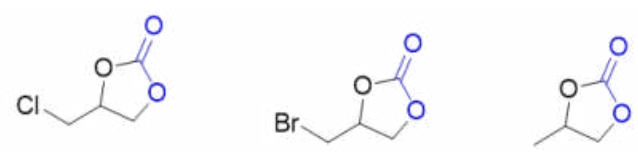

$99 \%$ (>99\%), $24 \mathrm{~h}$

$99 \%(>99 \%), 24 \mathrm{~h}$

$99 \%(>99 \%)^{\mathrm{c}}, 24 \mathrm{~h}$

Medium

difficulty
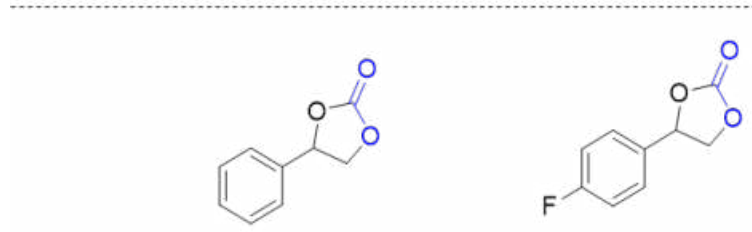

$99 \%(>99 \%), 24 \mathrm{~h}$

$97 \%(>99 \%), 36 \mathrm{~h}$
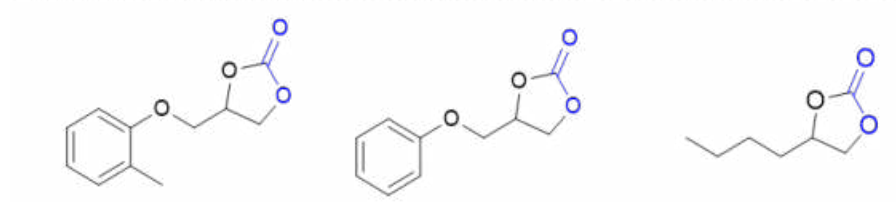

$90 \%(>99 \%), 36 \mathrm{~h}$

$91 \%(>99 \%), 36 \mathrm{~h}$

$99 \%(>99 \%), 36 \mathrm{~h}$

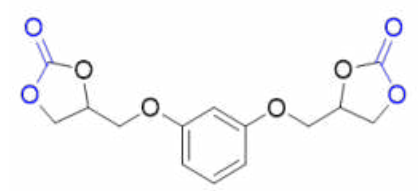

$90 \%(>99 \%), 36 \mathrm{~h}$

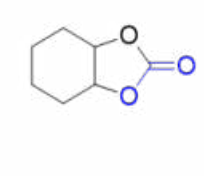

$22 \%(>99 \%), 36 \mathrm{~h}$

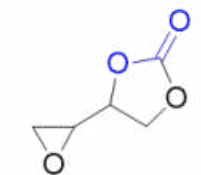

$25 \%$ (>99\%), $36 \mathrm{~h}$ Never before tested
B

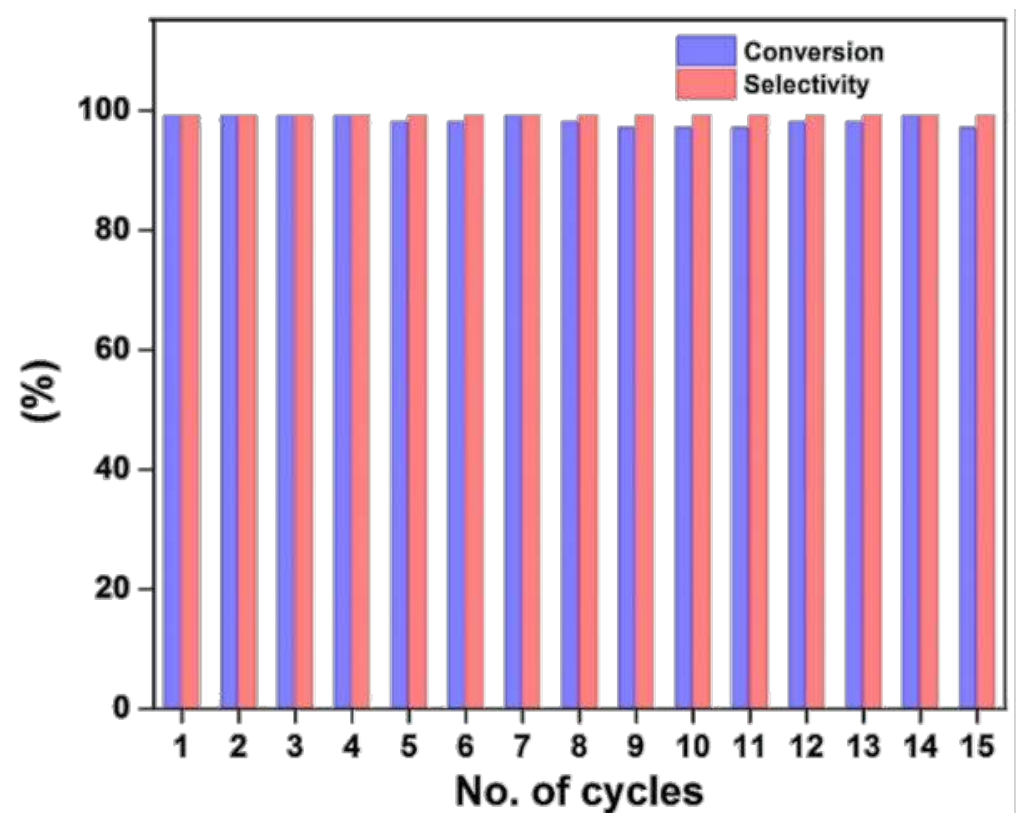

Figure 4. (A) Cycloaddition reaction of $\mathrm{CO}_{2}$ with various epoxides catalyzed by COP-222. Conversion yields for the corresponding catalytic reactions are given in percentages. The selectivities are reported in parentheses (B) Recyclability of COP-222 for 15 cycles. Each cycle was set up using the recovered catalyst and epichlorohydrine. aReaction conditions: substrate $(5 \mathrm{mmol}), \mathrm{COP}-222(30 \mathrm{mg}), \mathrm{CO}_{2}(1 \mathrm{~atm})$ and temperature

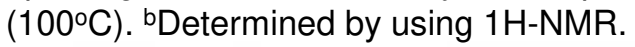




\section{ND-ERO Reaction Mechanism}

\section{Nucleophillic attack-driven Epoxide Ring Opening (ND-ERO) Mechanism}

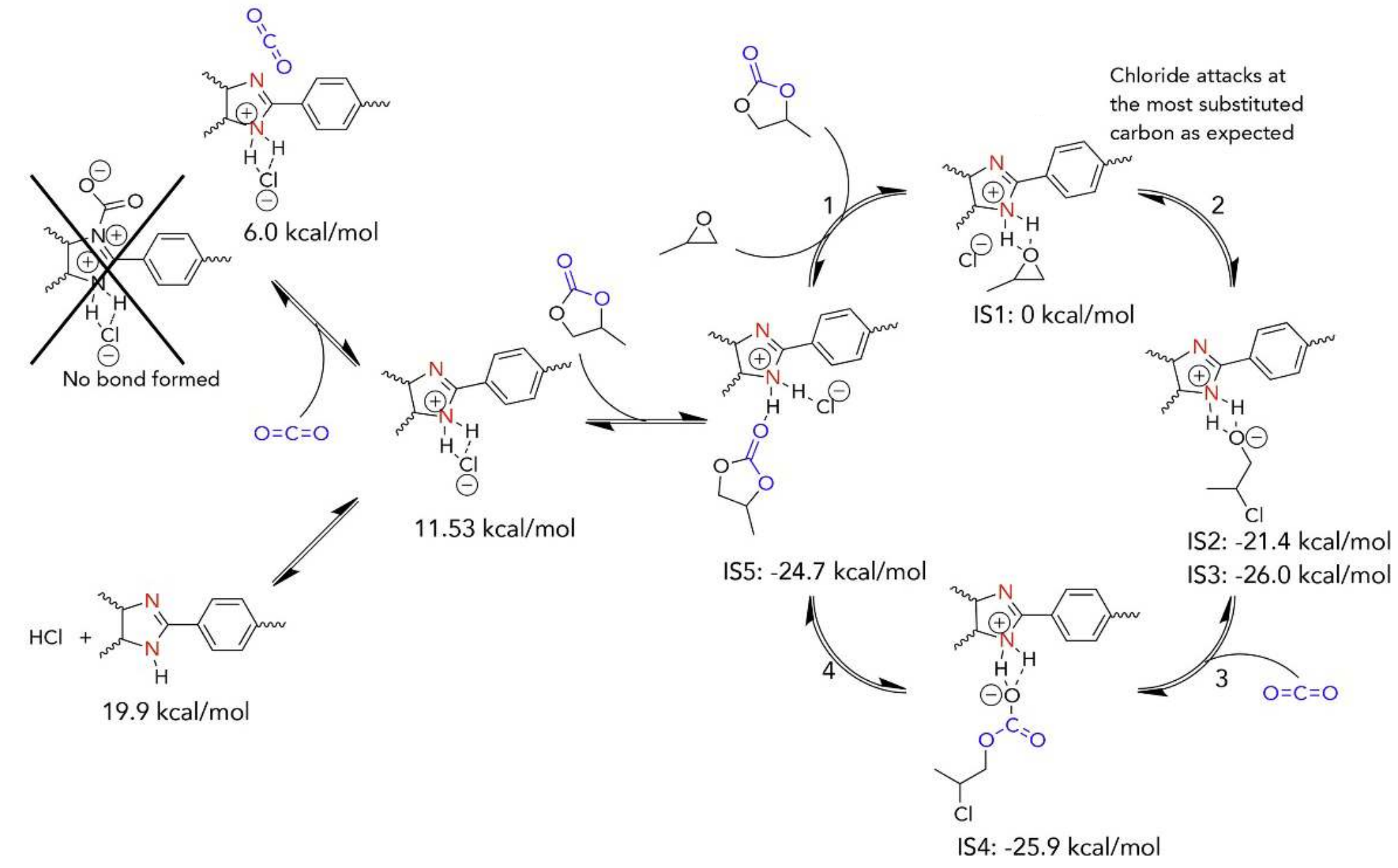

Figure 5. The Nucleophilic Attack-Driven Epoxide Ring Opening (ND-ERO) Reaction Mechanism Reaction mechanism for the COP-222 catalyst derived from quantum mechanics, including free energy reaction barriers. 


\section{Scalability and Cost}

\section{Bench-scale Testing (1.5L)}
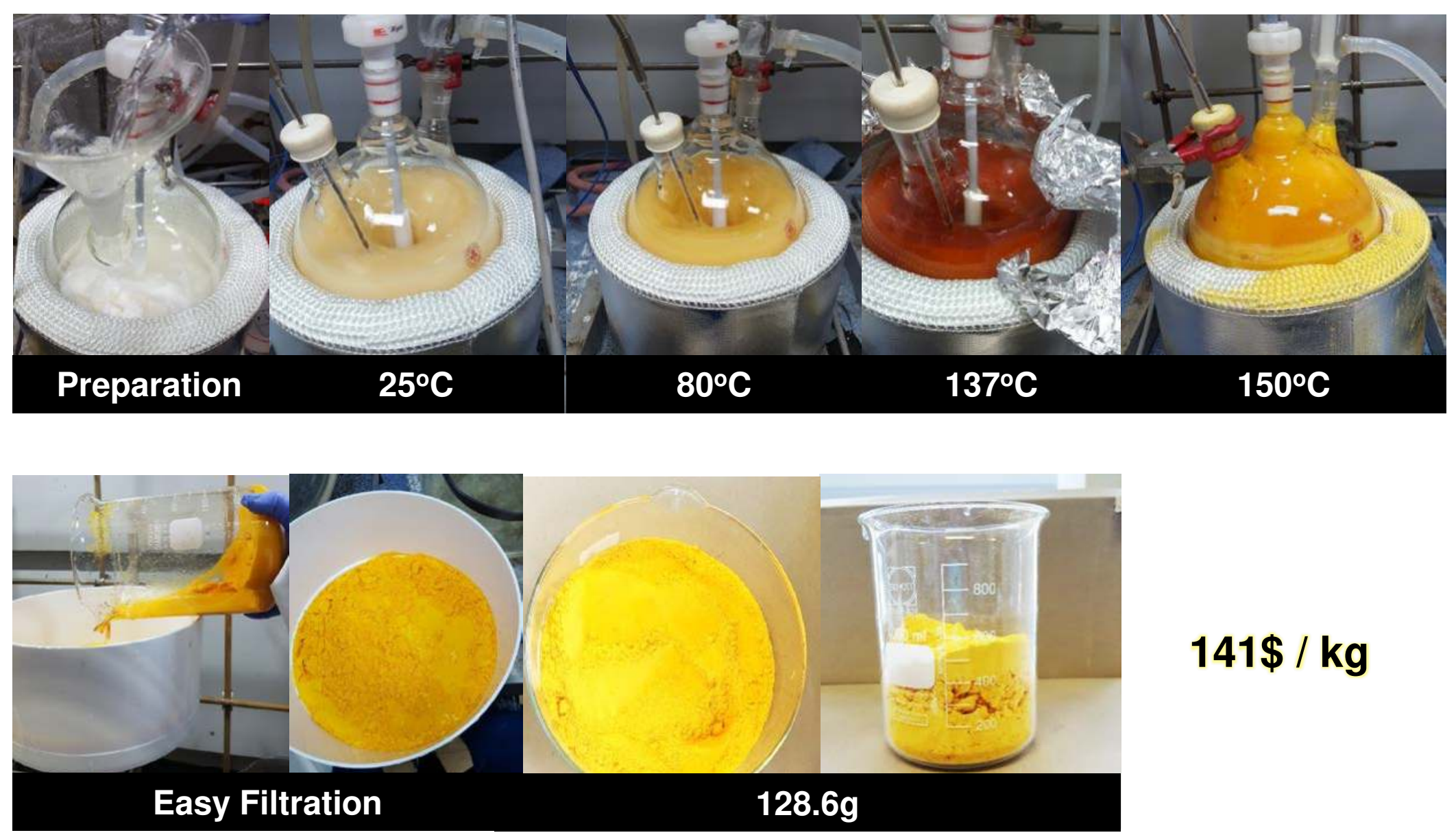

$141 \$$ / kg

Figure 6. Scale-up for COP-222 synthesis with terephthalaldehyde (200g) and ammonium chloride (320g) in dimethylformamide (1.5L) 


\section{Conclusions}

The imidazolinium catalyst that we developed herein addresses all 7 qualities and offers rapid implementation for $\mathrm{CO}_{2}$ reclamation.

(1) be free of metals; (2) be free of co-catalysts; (3) be free of high pressure requirements; (4) provide quantitative selectivity to cyclic carbonate (5) provide a wide substrate scope, including very hard substrates; (6) provide reusability; and (7) be inexpensive.

\section{Chem}

Volume 5, Issue 12, 12 December 2019, Pages 3232-3242

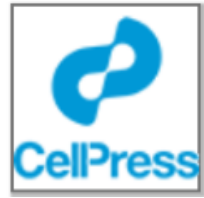

Article

Catalytic Non-redox Carbon Dioxide

Fixation in Cyclic Carbonates

Saravanan Subramanian ${ }^{1,7,8}$, Julius Oppenheim ${ }^{2,7}$, Doyun Kim ${ }^{3,7}$, Thien S. Nguyen ${ }^{1}$, Wahyu

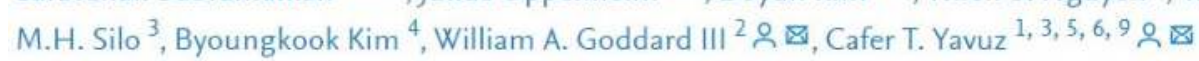

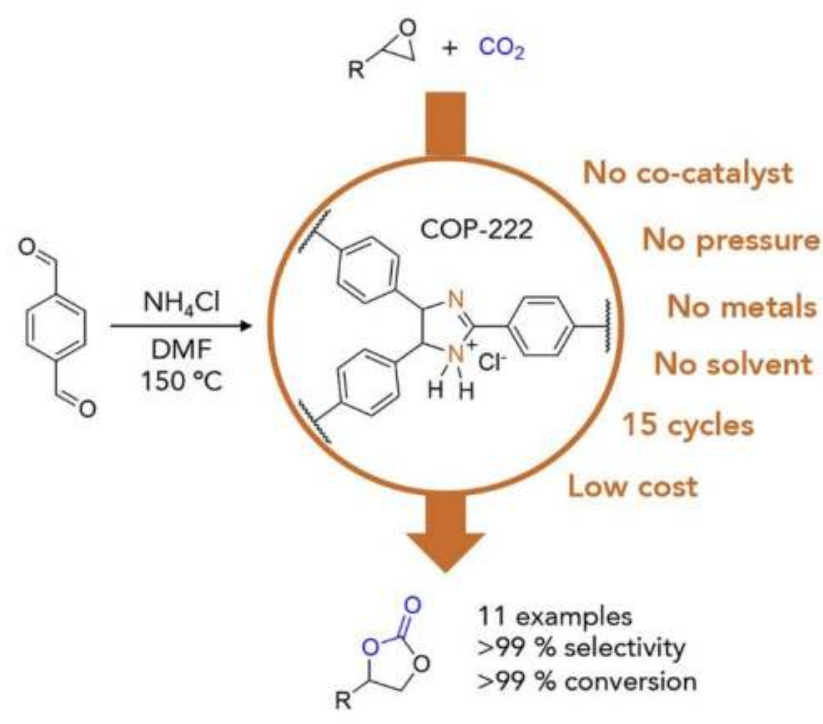




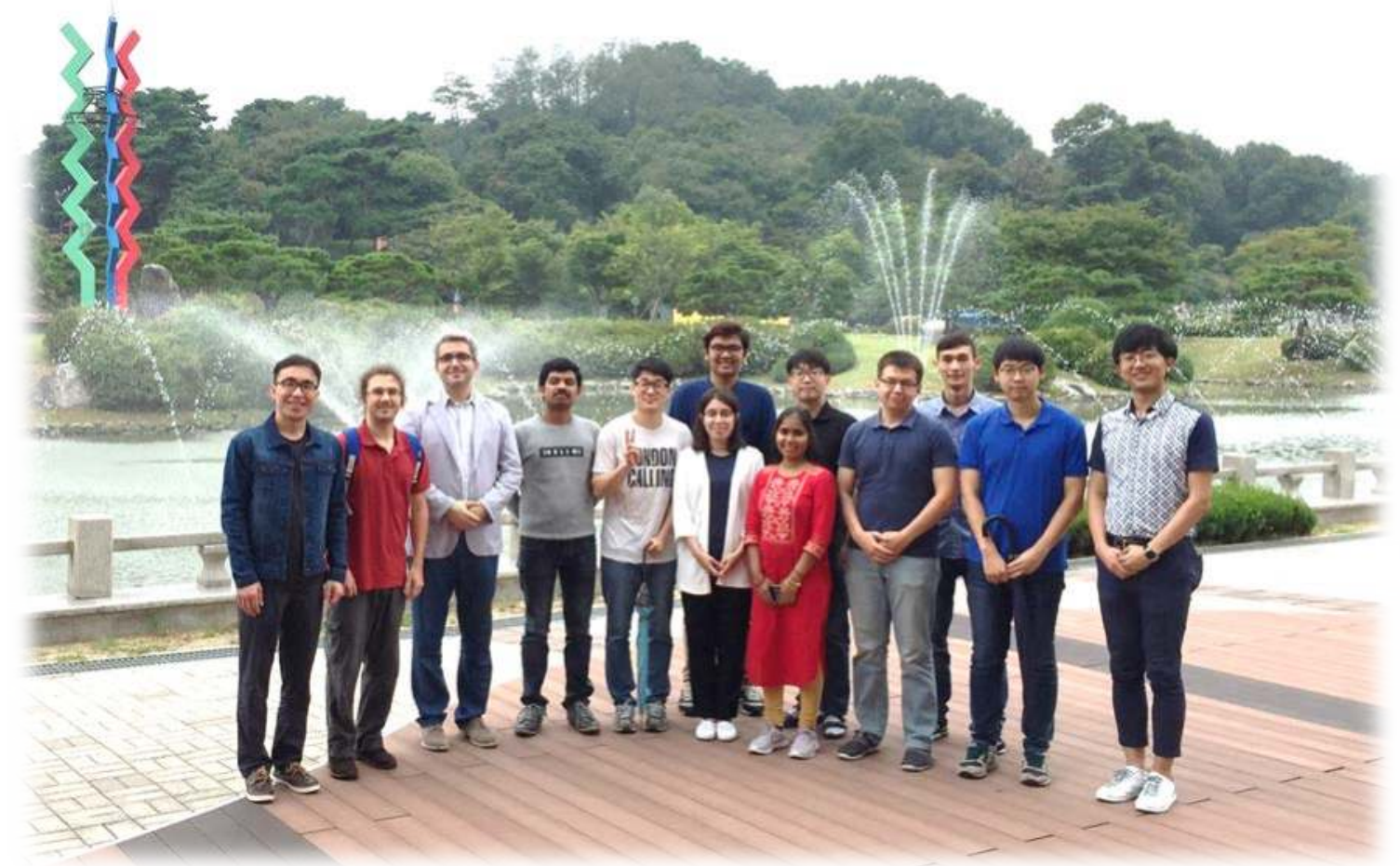

\section{Thank you for your listening!}

\section{KAIST}

